\title{
An overview of the question-response system in American English conversation
}

\author{
Tanya Stivers* \\ Max Planck Institute for Psycholinguistics. Wundtlaan 1, 6525XD Nijmegen, The Netherlands
}

\section{A R T I C L E I N F O}

\section{Article history:}

Received 1 December 2009

Accepted 1 April 2010

\section{Keywords:}

English

Questions

Polar (yes/no) questions

Content (WH) questions

Conversation

\begin{abstract}
A B S T R A C T
This article, part of a 10 language comparative project on question-response sequences, discusses these sequences in American English conversation. The data are video-taped spontaneous naturally occurring conversations involving two to five adults. Relying on these data I document the basic distributional patterns of types of questions asked (polar, $\mathrm{Q}$-word or alternative as well as sub-types), types of social actions implemented by these questions (e.g., repair initiations, requests for confirmation, offers or requests for information), and types of responses (e.g., repetitional answers or yes/no tokens). I show that declarative questions are used more commonly in conversation than would be suspected by traditional grammars of English and questions are used for a wider range of functions than grammars would suggest. Finally, this article offers distributional support for the idea that responses that are better "fitted" with the question are preferred.
\end{abstract}

(c) 2010 Elsevier B.V. All rights reserved.

\section{Introduction}

This paper discusses the range of ways that speakers ask and respond to questions and what speakers are doing through asking questions in American English conversation. As with other contributions to this volume, the data are a total of 350 questions occurring during video-taped spontaneous naturally occurring interaction as part of a cross-linguistic investigation of question-response sequences in naturally occurring spontaneous conversation. The analyses reported here focus on turns that sought information, confirmation or agreement, rather than those that were interrogatively formatted (e.g., syntactically) but did not appear to be used in search of such a response (e.g., outlouds) $(n=328)$. All data were collected in Southern California in the US. A total of 17 interactions were drawn on, and most questions (56\%) occurred in interactions involving between three and five native speakers of American English. The following sections describe the various question types, the range of social actions speakers employ questions to perform, and the designs of responses that occurred in these data. The operationalization of all coding categorized discussed here is described by Stivers and Enfield (this volume). As with other contributions to this volume, here the goal is to document how speakers design and use their questions and responses in ordinary spontaneous conversation.

\footnotetext{
* Permanent address: University of California, Los Angeles, 264 Haines Hall, 375 Portola Plaza, Los Angeles, CA 90095-1551, United States. Tel.: +31243521 408; fax: +31243521213.

E-mail address: Tanya.Stivers@mpi.nl.
} 


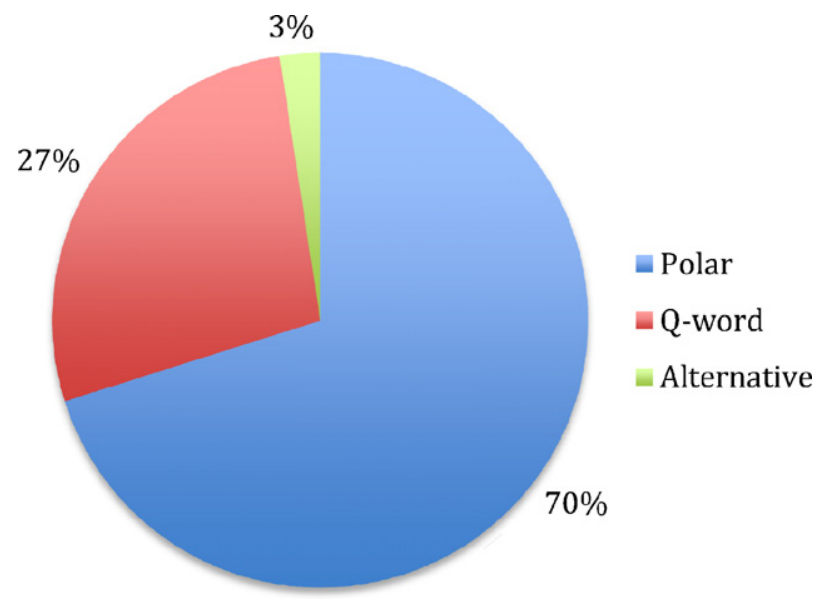

Fig. 1. Distribution of questions across question type.

\section{Results}

\subsection{Question types}

English conversation reflects three primary question types: polar questions, Q-word questions, and alternative questions (Jespersen, 1964; Quirk et al., 1985; Biber et al., 1999). The distribution though shows a bias similar to that found in many other languages in favor of polar questions as the dominant question type (see other contributions, this volume).

Fig. 1 shows that across a broad range of action types, ranging from requesting information to initiating repair and seeking agreement with an assessment, a substantial majority of all questions asked were polar questions ( $n=230$ ). Only $27 \%$ $(n=90)$ of all questions were Q-word questions, and alternative questions accounted for less than $3 \%$ of questions $(n=8)$. Freed documented a similar distribution in her study of questions in informal dyadic conversations (1994) suggesting that this distribution is representative of ordinary conversation in American English.

\subsubsection{Polar questions}

Polar questions are consistently said to be answered with a yes or a no in English. Interrogative, tag and declarative questions make up the dominant sub-types of polar questions. The interrogative format formed by subject/auxiliary inversion is generally treated as the most common and most neutral of polar questions (Jespersen, 1964; Quirk et al., 1985). For example, Quirk et al. (1985) assert that "Yes-no questions are usually formed by placing the operator before the subject and giving the sentence a rising intonation" (p. 807). There is no discussion of interrogatives being used for particular functions. By contrast, their discussion of other types of polar questions includes some indication of the functions for which they are used. Tags, they say, express "maximum conduciveness" (p. 810) thereby coercing particular answers in line with the question to a greater extent than other question types. Declarative questions are said to be "rather casual in tone" (p. 814).

In spontaneous conversation, however, declarative utterances were the dominant polar question type, as shown in Table 1. This distribution is also in line with that of Freed though her categorization differed slightly from ours (Freed, 1994). An example of a declarative question is shown in Extract 1. Here a man and woman are discussing the cost of boxing training-something Jess has been asking questions about over the past several sequences. At each of the second and third arrowed lines (lines 13 and 17), are canonical declarative polar questions. The intonation in both is rising, weakly so in the question in line 13 and more strongly in line 17. A third declarative polar question, less prototypical in design, is visible in line 4. Although complicatedly designed, ultimately the question requests confirmation that the "Sixty nine," offered by Mike as an amount is indeed a monthly cost. Confirmation takes the form of a nod initially and then a stronger form of affirmation with "That's tr^ue." Arguably the subsequent "Yeah" is agreeing with "Je:sus."

Table 1

Distribution of polar questions by sub-type.

\begin{tabular}{lc}
\hline Polar Q. type & Percent $/ n$ \\
\hline Declarative & $63 \%(n=145)$ \\
Interrogative & $31 \%(n=72)$ \\
Tag & $6 \%(n=13)$ \\
Total polar Q & $100 \%(n=230)$ \\
\hline
\end{tabular}


(1) Milk

1 Jess:

2

3

4

5

6 Jess:

7 Mike:

10

11 Jess:

12

13

14

15

16

17

18

Mike:

Mike: $\rightarrow$

Jess:

Jess:
How much does it cost tuh just (.) like (.) train.

(0.9)

Mike: $\quad$ Sixty nine,

Jess: $\rightarrow \quad$ Sixty nine d[ollars [what. uh month?

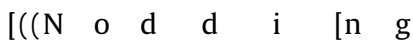

[J]e:s [us.

[That's $\operatorname{tr}^{\wedge}$ ue.

Yeah:.

Mike: $\quad$ Six times uh week

I: don't think so.

(0.5)

$>$ You 'on' wanna do that, $<$

No::t ((head shaking)) thuh six days uh wee:k_ ()

But I mean I wanna do it,

(.)

Mike: $\rightarrow \quad$ Y'r not that committed?,

Not to boxing, No,

Most declarative questions in these data involved some degree of rising final intonation, but only $50 \%(n=72)$ had strongly rising intonation (as transcribed by a question mark or a question mark with a comma). A further $32 \%(n=46)$ had only a slight rise (transcribed with comma intonation). Of the remaining $18 \%(n=27)$, all but three cases had falling intonation. In line with previous studies that have suggested the declarative questions do not rely exclusively on intonation (Geluykens, 1988; Weber, 1993), this distribution also suggests this. But it seems in point to observe too that $87 \%(n=126)$ of these declarative questions were about the question recipient (e.g., her wants or likes as in Example 1 lines 13 and 17), or were about something that the question recipient would be expected to know more about (e.g., questioning the prior speaker's utterance in line 4 of Example 1). Thus, most declarative questions were "B-event statements" (Labov and Fanshel, 1977; Weber, 1993; Heritage and Roth, 1995).

Interrogatively formatted questions accounted for one-third of all polar questions (see Table 1). Example 2 shows a canonical example. Here a couple is having dinner and Kim, following a lapse in the conversation, asks about the broaching of a topic among Mark's co-workers. The question involves both the inversion of the do-auxiliary and the shift from the assertive forms "somebody" and "something" typical in the declarative context to the "non-assertive" "anybody" and "anything" typical of the interrogative context (Quirk et al., 1985).

(2) $\mathrm{RD}$

$1 \quad$ Kim: $\rightarrow \quad$ So did anybody say anything about thuh bar tuhday?

$2 \quad(2.0)$

3 Mark: Yeah,

4 (.)

5 Mark: Customers,

Tag questions were relatively rare in English (Table 1) though there are a number of tags possible. Comprising only $6 \%$ of polar questions, tags included both clausal "isn't he" or "did she" forms (Example 3 ) and, far more commonly ( $77 \%$ of the time; $n=10$ ), lexical forms such as "right" and "huh" (Example 4).

(3) Milk

1 Jess: $\quad$ That's kind of a lot for breakfast don't=ya think?,

2 Mike: $\quad$ Nah::, I thin' iz- I think it's great.

(4) RD

1 Kim:

2

3 Mark:-

(Very good.)

(6.5)

Mark: $\rightarrow \quad$ Not bạd for free huh?

(0.3)

Kim: $\quad H \underline{\mathrm{m}} \mathrm{mm}$. 


\subsubsection{Q-word questions}

Q-word questions were relied on just over a quarter of the time in the English conversations examined here. When used they involved the expected range of Q-words (who, what, where, when, why and how). Although such Q-words can be used in situ in conversation (Schegloff et al., 1977), this was extremely rare in this sample. Example 1 shows a non-prototypical instance in line 4, but the turn begins with a Q-word question and this is followed by a polar question with the candidate "a month". In these data Q-word questions were nearly always designed with the Q-word in TCU initial position (Example 5).

(5) Milk

1 Jess:

How much does it cost tuh just (.) like (.) train.

2

3 Mike: $\quad$ Sixty nine,

Less frequently Q-word questions were prefaced by, for instance, and, but, or so as shown in Example 6. Here the Q-word question "Why didn't=chu buy any uh these." (line 5) is prefaced by "So".

(6) RD

$1 \quad$ Kim: $\quad$ These're good so are they all different kinds?,

2 (.)

3 Mark: Yeah there's uh:: (.) I got thuh list_

$4 \quad(0.6)$

$5 \quad$ Kim: $\rightarrow \quad$ So why didn't=chu buy any uh these.

$6 \quad(0.2)$

$7 \quad$ Mark: $\quad$ Cuz I haven't even tried 'em. This is thuh first time

8 I'm trying 'em out, tonight.

The distribution of types of Q-word questions in shown in Fig. 2.

The most common questions were "What" questions. Among these, most $(n=13)$ involved questions about prior talk; also prominent in the category were questions asking about objects ("What's this.") $(n=10)$ and events (e.g., "What'd you do last night.") $(n=10)$. "How" questions were the second largest category of Q-word questions. Most of these involved inquiries about personal/event states ("How are you."; "How was it.") $(n=13)$; another subset concerned quantity ( $n=5)$; the rest involved questions about manner and length $(n=3)$.

\subsubsection{Alternative questions}

As shown in Fig. 1, alternative questions were seldom asked in these English conversations. Example 7 shows an instance. Here two full questions are placed together conjoined by or.

(7) SB1

Lanie: $\rightarrow \quad$ Were you drunk or were you sober.

Mandi: $\quad$ You guys have uh good day:,

Ingrid: Bye: you too:

Ingrid: I wasn't- I wasn't sober but ()

((other speakers in the room distract Ingrid and Lanie))

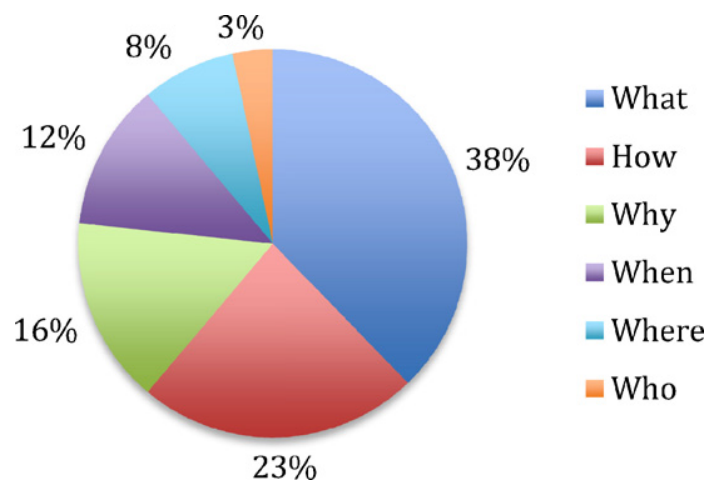

Fig. 2. Distribution of Q-word questions by categories. 
By contrast, Extract 8 shows an appendor question (Sacks, 1992: 660; Schegloff, 1997) seeking clarification which conjoins two purpose clauses "to be friends" versus "to be more than friends".

(8) SB1

1 Ingrid: $\rightarrow$

I know that it's just too hard b't_ Like it is too

2

hard_ It's disrupting both of our li:ves.

3 Zoe: ((laughing loudly about other conversation))/(1.5)

$4 \quad$ Mandi: $\rightarrow \quad$ Tuh be friends, or tuh be $(0.2)$ more than friends

5 Ingrid: Tuh be more than friends is disrupting both of our

lives.

Thus, speakers of English have a variety of resources for formatting questions. They can design a question to make relevant a yes/no response (polar), a relevant phrasal or clausal response (Q-word), or a forced choice between two alternatives. Within the dominant category of polar questions, speakers of English appear to rely most frequently on a turn design devoid of lexico-morpho-syntactic marking, relying instead on intonation and epistemic resources despite having available interrogative syntax and tags, although this varies by the social action being implemented.

\subsection{Social action}

Questions are traditionally defined as sentence types that seek information from someone being treated as knowing by someone who is unknowing (e.g., König and Siemund, 2007). However, as Steensig and Drew point out, "even though information (or confirmation) may be part of what a question is built to get, this seems to be virtually never...what questioning in interaction is centrally about" (Steensig and Drew, 2008: 9). Partially, this is a matter of how finely one slices the data. For instance, in Extract 2 one could argue that Kim is seeking information with "So did anybody say anything about thuh bar tuhday?", but this same turn could be analyzed as a topic proffer designed to elicit a telling about what Mark's coworkers said to him, at least in the event of an affirmative answer.

In these data examples of questions that seem primarily concerned with securing information are readily available. An example is shown in Extract 5. The question is part of a series of questions about Mike's hobby, boxing. Still, as shown in Table 2, a minority of questions were identified as primarily concerned with requesting and obtaining information. Thus, most questions were identified as primarily doing something else in the interactional sequence. For instance, nearly $1 / 3$ of questions were deployed to initiate repair on someone else's prior turn. An example of this is shown in Extract 8 at line 4.

Beyond information requests and other initiations of repair, a third prominent category of social action was confirmation requests. These comprised $1 / 5$ of all questions. The questions at lines 13 and 17 of Extract 1 exemplify this social action. The remaining $5 \%$ of questions were relatively evenly divided between assessments where people were seeking agreement (e.g., see Extracts 3-4), turns that suggested, offered or requested something, and turns that performed "something else". Only 2 cases fell into this category and these were a pre-announcement "Can I tell you thuh truth?" and a tease.

Considering the intersection of question type and social action, we can first see that speakers rely on all main question types to request information, whereas for other actions they rely much more heavily on polar questions. Within polar questions we can further observe in Table 3 that information requests rely much more heavily on interrogatives. Thus, the

Table 2

Distribution of social actions being implemented by question type.

\begin{tabular}{lccc}
\hline Social action & Polar & Q-word & Totals \\
\hline Information request & $44 \%(n=63)$ & $50 \%(n=71)$ & $6 \%(n=8)$ \\
Other initiation of repair & $82 \%(n=82)$ & 0 & 0 \\
Confirmation request & $100 \%(n=70)$ & 0 & 0 \\
Assessment & $100 \%(n=8)$ & 0 & 0 \\
Suggestion/offer/request & $100 \%(n=6)$ & 0 & 0 \\
Other (e.g., pre-announcement; tease) & $100 \%(n=1)$ & 0 & $21 \%(n=70)$ \\
Totals & $70 \%(n=230)$ & $27 \%(n=8)$ & 0 \\
\hline
\end{tabular}

Table 3

Distribution of social action type by question type among polar questions.

\begin{tabular}{|c|c|c|c|c|}
\hline Social action & Declarative & Interrogative & Tag & Totals \\
\hline Information request & $8 \%(n=5)$ & $92 \%(n=58)$ & 0 & $29 \%(n=63)$ \\
\hline Other initiation of repair & $94 \%(n=77)$ & $5 \%(n=4)$ & $1 \%(n=1)$ & $38 \%(n=82)$ \\
\hline Confirmation request & $77 \%(n=54)$ & $9 \%(n=6)$ & $14 \%(n=10)$ & $33 \%(n=70)$ \\
\hline Totals & $63 \%(n=136)$ & $32 \%(n=68)$ & $5 \%(n=11)$ & $N=215$ \\
\hline
\end{tabular}


Table 4

Next speaker selection: use of gaze and domain of authority.

\begin{tabular}{|c|c|c|c|}
\hline Speaker gaze & Question primarily in addressee's domain & Question not primarily in addressee's domain & Totals \\
\hline At addressee & 117 & 23 & $88 \%(n=140)$ \\
\hline Not at addressee & 19 & 1 & $12 \%(n=20)$ \\
\hline Totals & $85 \%(n=136)$ & $15 \%(n=24)$ & $n=160$ \\
\hline
\end{tabular}

view that interrogatives are a standard way to ask a question in English appears to be true for information requests, though not for other sorts of action types.

Declarative questions remain more common for initiations of repair and confirmation requests.

Nearly all of the tags in the corpus were used to request confirmation (e.g., "Those are shri:mp fajitas ri:ght,"). Tags were also occasionally used to make assessments (e.g., "Not bad for free: huh?,") ( $n=2$ ). Thus, although tag questions are not prototypical for any particular action type, speakers rely on them most frequently to implement this social action. These facts suggest that for speakers designing social actions, lexico-morpho-syntax is relied on in systematic ways, ways that further work could likely tease apart. Thus, in considering how question recipients come to understand what sort of action is being put forward and how they should respond, lexico-morpho-syntax is clearly critical.

\subsection{Next speaker selection}

A primary way in which a speaker comes to take a turn at talk is through having been selected to do so (Sacks et al., 1974). Various resources have been identified for selecting a next speaker including explicit addressing through gazing at the addressee while, for instance, asking a question or addressing him/her by name in the course of asking the question (Sacks et al., 1974; Lerner, 2003). A third key resource for selecting next speaker is what Lerner terms "tacit addressing" (Lerner, 2003). Lerner defines tacit addressing as a turn design such that the requirements to respond to the (for example) question "limit eligible responders to a single participant" (p. 190). The question remains though as to how often next speakers are in fact selected in conversation and by what means.

Overwhelmingly, questioners in these data selected next speakers. Considering only the questions asked in multi-party conversation, 93\% $(n=165)$ of questions selected a next speaker. Eighty-eight percent of questions in multi-party conversations were delivered with speaker gaze and $85 \%$ of questions were identified as in the addressee's particular domain of authority. Only $4 \%$ of questions $(n=7)$ made use of an address term. ${ }^{1}$

Moreover, as shown in Table 4, in most cases speakers make use of both gaze and domain of authority. However, given the various constraints on gaze, in particular that it must be seen by both the selected and the non-selected individual to be useful (Lerner, 2003), speakers clearly also rely on tacit addressing through domain of authority.

An example of a case where a speaker relies on domain of authority (or tacit addressing) to select next speaker is shown in Extract 9. Here, Patrick, Lisa, Jane and Mary are eating dinner together at a restaurant. Patrick has disclosed that he normally looks not at people's eyes when he talks to them but at their mouth. This is treated as a strange behavior by most of the other interlocutors. In lines 2/4 Lisa asks whether this blanket statement of not looking at people's eyes would hold even in the case of a girlfriend.

(9) EP

1 Patrick:

[like () staring.

Lisa: $\rightarrow \quad$ [So even like: uh girl [frie:nd? Even like uh girlfriend,=

Mary:

[huh ((laugh particle))

Lisa: $\quad=$ you don't look at her eyes,

Patrick: (Well yeah some-

Jane: How could=you- I [could never $\mathrm{d}^{\wedge} \underline{\mathrm{o}}$ tha:(h)t.

Patrick: [Yeah I do- Not all thuh time but like-

(1.1) most uh thuh time. I just look at thuh mouth. I

don't look at [thuh eye:s_ I think it's so bo:ring...

10

11 Lisa:

[hhh huh

\footnotetext{
${ }^{1}$ Numbers here for some categories differ from those given earlier in terms of percentage because, in some cases, I could not assess speaker gaze, for instance.
} 
Table 5

Distribution of response type by question type.

\begin{tabular}{|c|c|c|c|c|}
\hline Response type & Polar & Q-word & Alternative & Totals \\
\hline Answer & $80 \%(n=183)$ & $68 \%(n=61)$ & $63 \%(n=5)$ & $76 \%(n=249)$ \\
\hline Non-answer response & $16 \%(n=36)$ & $24 \%(n=22)$ & $38 \%(n=3)$ & $19 \%(n=61)$ \\
\hline No response & $5 \%(n=11)$ & $8 \%(n=7)$ & 0 & $5 \%(n=18)$ \\
\hline Totals & & & & $N=328$ \\
\hline
\end{tabular}

During the entire articulation of her question and the silence which follows at line 5, Lisa maintains her gaze on her tortilla chip with which she is scooping guacamole from a bowl. Despite the lack of gaze, only Patrick is a relevant next speaker here, both because only he has indicated that he does not look at people's eyes and because, in the present company, based on how they talk elsewhere, only he would have a girlfriend. The use of "even" also disambiguates since it is clearly a follow up to prior discussion of his strange gaze behavior.

In terms of selection then, the data suggest that selection of next speaker is overwhelmingly done when asking questions and that the use of gaze and primary domain of authority are the two most common ways of selecting a next speaker in English multi-party conversation.

\subsection{Fittedness of question and response}

Thus far we have discussed how questions are designed and what they are doing, interactionally, when a speaker utters them. The question turns on which I am focusing all make response relevant following the question (Schegloff, 1968). Prior work has documented that certain responses are preferred over others in terms of their structural "fit." For instance, answers are preferred over non-answer responses (Clayman, 2002; Stivers and Robinson, 2006); confirmations are preferred over disconfirmations (Heritage, 1984); answers which accept the terms of the question, and accept reduced agency over them, are preferred over those that resist either of these dimensions (Raymond, 2003; Heritage, forthcoming; Stivers, forthcoming; Stivers and Hayashi, 2010). All of these more fitted responses are typically delivered as "preferred" responses in that they are typically delivered more quickly than the alternative, without mitigation and without accounts (Heritage, 1984; Pomerantz, 1984; Stivers et al., 2009).

These findings have been shown primarily in terms of how responsive turns are designed. For instance, non-answer responses such as "I don't know" are, in and of themselves, accounts for not providing an answer, and frequently accounts for why the speaker does not know are also provided (Stivers and Robinson, 2006). Similarly, disconfirming answers to questions are generally prefaced, mitigated and accounted for, whereas confirming answers are generally delivered straightforwardly without prefaces, mitigation or accounts (Heritage, 1984). Thus, existing research has suggested regularities and preferences that we would expect to see evidenced in distributions if these regularities apply across the range of action types discussed here. This section explores whether these expectations are borne out by the data.

Table 5 shows that indeed most questions are responded to with answers. Only $5 \%$ of all questions received no response. ${ }^{2}$

Moreover, as shown in the totals column for non-answer responses, less than $20 \%$ of the time were questions responded to with non-answer responses. Because of this project's effort to keep the answer category as clean and straightforward as possible, non-answer responses included not only “I don't know” and “I can't remember”, but also less committal “Maybe” or "Probably" responses and less direct answers. For instance, in Extract 10, Jim and his wife are visiting Roy and his family who are staying near where celebrity Dennis Rodman lived at one time. Jim's question appears to presuppose that Rodman still lives in the area.

(10) PC

1 Jim:

Have you seen D- have you seen Dennis Ro:dman?

2

3 Roy: $\rightarrow \quad$ He sold his place. $=$

4 Jim: $\quad$ =Yeah I know

Roy's response declines to provide a direct answer (yes or no or a repetitional version such as "I've not seen him"), most likely because either answer would imply something different if Rodman still lived in the neighborhood versus if he had moved. Instead, he implies that he hasn't seen him but focuses instead on adjusting the presupposition that Rodman still lives in the area (which, according to line 3, he does not). For this reason, the number of non-answer responses also may be slightly inflated. Despite this, answers were still dominant as a response to questions in conversation. ${ }^{3}$ Eighty percent of

\footnotetext{
2 This number is likely inflated since in some cases answers did come after an interruption or after the questioner pursued a response through another question. This would not have been captured in the coding.

${ }^{3}$ Subsequent to this study, Stivers and Hayashi pursued a subset of these cases further under the rubric of "transformative answers" (2010).
} 
Table 6

Distribution of response form.

\begin{tabular}{lc}
\hline Answer form & Percent $/ n$ \\
\hline Yes/no type answer & $77 \%(n=137)$ \\
Repetitional answer & $6 \%(n=10)$ \\
Combination & $17 \%(n=30)$ \\
Marked interjection & $1 \%(n=2)$ \\
\hline
\end{tabular}

polar questions, $68 \%$ of Q-word questions, and $63 \%$ of alternative questions received answers. Thus, distributionally, these data are in line with qualitative work suggesting that answers are more fitted to the actions employed by questions than non-answer responses are insofar as they are more common. Answers are also significantly more likely to be faster in English (Stivers et al., 2009).

Among answers to polar questions, confirmations were, as would be expected from prior research, more common than disconfirmations. Of polar questions that received an answer, $72 \%(n=130)$ received a confirmation whereas $28 \%(n=50)$ received a disconfirmation. Confirmations have also been found to be delivered significantly faster than disconfirmations in English (Stivers et al., 2009).

In terms of the forms answers took in response to polar questions, the interjections yes and no were far more common (see examples 2-4 above). As shown in Table 6, 77\% of all answers were done with one of these items (and most combinations are yes or no initial as well, so this percentage is actually substantially higher for first TCUs).

Only $6 \%$ of answers involved repeats of the question. An illustration is shown in Extract 11. Jess has just revealed that she would not be interested in training 6 days every week to box. Mike has accused her of not being "that committed". Jess's question at like 5 challenges Mike's self-assessment in line 1. In form, though, it remains a polar question that makes relevant yes or no but instead receives a repeat as a confirmation.

(11) Milk

1 Mike:

I'm uh committed kinda gụy.

2

3 Jess:

Uh huh:, $\quad$ ((nodding))

5 Jess:

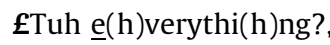

$6 \quad$ Mike: $\rightarrow$

7 Jess: E:verything. ((slight nod))

Mm hm:,

Pragmatically marked interjections such as "right" or "absolutely" were rare in these data (see Stivers, forthcoming for a detailed discussion of one type).

Across the range of response types that vary by fittedness (answers versus non-answer responses; confirmations versus disconfirmations; type conforming versus non-type conforming), in each case the more fitted response was more frequent. Turn allocation can be conceptualized as another sort of response fittedness in the sense that a question is designed not only to receive a particular sort of response within a particular time but also by a particular individual. Stivers and Robinson (2006) show that participants orient to responses by selected next speakers as preferred to those offered by non-selected coparticipants insofar as recipients would defer to the selected speaker to answer even when capable of answering the question, and insofar as questioners treated an answer from an unselected next speaker as a violation of the norm in favor of speaker selection. In these data, in $94 \%$ of cases where a next speaker was selected, that individual was the one to respond. Thus, at least for English speakers in conversation, both qualitative and quantitative evidence supports the claim that when turns are allocated through addressing, whether tacitly or explicitly, selected individuals have an obligation to, and usually do, fulfill their responsibility by responding to the question posed.

Finally, most of what we have discussed about question-response sequences has been in the vocal channel even though some questions have kinesic components to them (e.g., Rossano et al., 2009; Enfield, 2009). We did though examine question recipients' response designs for whether they were vocal or kinesic. In these data most of the kinesic responses were head nods and shakes in response to polar questions (Maynard, 1987; Kendon, 2002). Very few kinesic responses were anything else. $^{4}$

In the context of story tellings, nods have been shown to be used and responded to differently than other acknowledgments such as $\mathrm{mm} \mathrm{hm}$ and $u h \mathrm{huh}$ (Stivers, 2008). Thus, it is also possible that, as answers to questions, vocal and kinesic responses differ in their communicative import. In terms of distribution, this appears likely. Nearly all responses include a vocal component ( $93 \%$ of responses) and most involve only a vocal response (58\% of responses). However, $35 \%$ of all

\footnotetext{
${ }^{4}$ There was one case in which a gesture indicating the speaker was offered in response to a Q-word question and one that involved a shrug as a nonanswer response. Pointing was a logical possibility but in these data rarely occurred as an answer.
} 
responses included both a vocal and a kinesic response (e.g., Extract 11 involved a small nod in overlap with the repeat of "E: verything."). Only 7\% of all responses included only a visible response. Extract 1, line 5 shows an example. Here, Jess seeks clarification on the units meant by Mike when he told her that training for boxing cost "Sixty nine". She offers a candidate of "uh month?" (line 4), which he confirms with a series of head nods (line 5). Although he subsequently adds "That's tr^ue.", at this point she has already treated his nodding as a sufficient confirmation in her subsequent "Je:sus." (line 6), which adopts a stance towards (the now confirmed) sixty nine dollars per month as outrageous. ${ }^{5}$ As with confirmations and answers, responses to questions that included a kinesic component were delivered significantly faster than vocal-only responses (Stivers et al., 2009).

\section{Conclusions}

This article has documented the range of ways in which speakers of American English design their questions and responses in conversation. What I have shown in terms of lexico-morpho-syntactic features of question design is in line with authoritative English grammars-American English speakers rely on polar, Q-word and alternative questions to do questioning. Within polar questions, speakers rely differentially on interrogatives, declaratives and tags. However, whereas non-usage-based authoritative grammars indicate that interrogatives are the most canonical means of asking a question (Jespersen, 1964; Quirk et al., 1985), these data suggest that this depends on the social action. Most polar questions were posed with declarative syntax. However, restricting to only questions that were primarily about obtaining information as a response, interrogatively marked questions were more common.

Related to this, is what questioning is in the service of. Some linguists have claimed questions are primarily concerned with obtaining information (e.g., König and Siemund, 2007). Although this was certainly an important function of questions in these data, most questions were concerned with doing other sorts of social actions (e.g., initiating repair, securing agreement, etc.). And clearly the intersection between sentence type (e.g., declarative versus interrogative) and social action is critical for such interests as understanding how directly a speaker indicates their action or pursues response to it (Brown and Levinson, 1987 [1978]), and for understanding the sequential environments in which particular forms are used (Curl and Drew, 2008). A related view is that the more features of questioning a social action is designed to include (speaker gaze, rising intonation, interrogative morpho-syntax, recipient epistemic bias), the more response mobilizing the utterance is (Stivers and Rossano, 2010).

Finally, this article has documented that responses that are more fitted to the question (in terms of being action-aligned with an answer, providing confirmation, providing a type conforming answer, or being responded to by the selected individual) are indeed more common. This suggests a bias across interaction towards cooperative responses (for more extensive discussion of cooperation in human social interaction see Enfield and Levinson, 2006)-cooperative in the sense that they provide the requested action, they match the questioner's bias, they assent to the questioner's terms rather than insisting on their own agency or independence (Heritage, 1998). From here we need to develop a better understanding of the relationships between question design, action and response design work. We also have yet to understand which aspects of these domains are heavily culturally shaped and which are universal.

\section{References}

Biber, Douglas, Hohansson, Stig, Leech, Geoffrey, Conrad, Susan, Finegan, Edward, 1999. Longman Grammar of Spoken and Written English. Longman, London.

Brown, Penelope, Levinson, Stephen C., 1987 [1978]. Politeness: Some Universals in Language Usage. Cambridge University Press, Cambridge.

Clayman, Steven, 2002. Sequence and solidarity. In: Lawler, E.J., Thye, S.R. (Eds.), Advances in Group Processes: Group Cohesion, Trust and Solidarity. Elsevier Science, Oxford, pp. 229-253.

Curl, Traci S., Drew, Paul, 2008. Contingency and action: a comparison of two forms of requesting. Research on Language and Social Interaction 41, 129-153. Enfield, N.J., 2009. The Anatomy of Meaning: Speech, Gesture and Composite Utterances. Cambridge University Press, Cambridge.

Enfield, N.J., Levinson, Stephen C. (Eds.), 2006. Roots of Human Sociality: Culture, Cognition, and Interaction. Berg, London, England.

Freed, Alice F., 1994. The form and function of questions in informal dyadic conversation. Journal of Pragmatics 21, 621-644.

Geluykens, Ronald, 1988. On the myth of rising intonation in polar questions. Journal of Pragmatics 12, $483-494$.

Heritage, John, 1984. Garfinkel and Ethnomethodology. Polity Press, Cambridge.

Heritage, John, 1998. Oh-prefaced responses to inquiry. Language in Society 27, 291-334.

Heritage, John, forthcoming. Constructing and navigating epistemic landscapes: progressivity, agency and resistance in 'yes/no' versus 'repetitive' responses. In: de Ruiter, J.P. (Ed.), Questions: Formal, Functional and Interactional Perspectives. Cambridge University Press, Cambridge.

Heritage, John, Roth, Andrew, 1995. Grammar and institution: questions and questioning in the broadcast news interview. Research on Language and Social Interaction 28, 1-60.

Jespersen, Otto, 1964. Essentials of English Grammar. The University of Alabama Press, Tuscaloosa, AL.

Kendon, Adam, 2002. Some uses of the head shake. Gesture 2, 147-182.

König, Ekkehard, Siemund, Peter, 2007. Speech act distinctions in grammar. In: Shopen, T. (Ed.), Language Typology and Syntactic Description. Cambridge University Press, Cambridge, pp. 276-324.

Labov, William, Fanshel, David, 1977. Therapeutic Discourse: Psychotherapy as Conversation. Academic Press, New York.

Lerner, Gene, 2003. Selecting next speaker: the context sensitive operation of a context-free organization. Language in Society 32, $177-201$.

Maynard, Senko K., 1987. Interactional functions of a nonverbal sign: head movements in Japanese dyadic casual conversation. Journal of Pragmatics 11, 589-606.

Pomerantz, Anita, 1984. Agreeing and disagreeing with assessments: some features of preferred/dispreferred turn shapes. In: Atkinson, J.M., Heritage, J. (Eds.), Structures of Social Action: Studies in Conversation Analysis. Cambridge University Press, Cambridge, pp. 57-101.

\footnotetext{
${ }^{5}$ Because the nodding continues through the production of "uh month?" it could be taken as a confirmation of the candidate answer as well.
} 
Quirk, Randolph, Greenbaum, Sidney, Leech, Geoffrey, Svartvik, Jan, 1985. A Comprehensive Grammar of the English Language. Longman, London.

Raymond, Geoffrey, 2003. Grammar and social organization: yes/no interrogatives and the structure of responding. American Sociological Review 68, 939-967.

Rossano, Federico, Brown, Penelope, Levinson, Stephen C., 2009. Gaze, questioning and culture. In: Sidnell, J. (Ed.), Conversation Analysis: Comparative Perspectives. Cambridge University Press, Cambridge, pp. 187-249.

Sacks, Harvey, 1992. Lectures on Conversation vol. 1 (fall 1964-spring 1968) Blackwell, Oxford.

Sacks, Harvey, Schegloff, Emanuel A., Jefferson, Gail, 1974. A simplest systematics for the organization of turn-taking for conversation. Language 50, 696-735.

Schegloff, Emanuel A., 1968. Sequencing in conversational openings. American Anthropologist 70, 1075-1095.

Schegloff, Emanuel A., 1997. Practices and actions: boundary cases of other-initiated repair. Discourse Processes 23, $499-545$.

Schegloff, Emanuel A., Jefferson, Gail, Sacks, Harvey, 1977. The preference for self-correction in the organization of repair in conversation. Language 53, $361-382$.

Steensig, Jakob, Drew, Paul, 2008. Introduction: questioning and affiliation/disaffiliation in interaction. Discourse Studies $10,5-15$.

Stivers, Tanya, 2008. Stance, alignment and affiliation during story telling: when nodding is a token of affiliation. Research on Language and Social Interaction 41, 29-55.

Stivers Tanya, forthcoming. Morality and question design: 'of course' as contesting a presupposition of askability. In: Stivers, T. Mondada, L., Steensig, J. (Eds.), The Morality of Knowledge in Conversation. Cambridge University Press, Cambridge.

Stivers, Tanya, Enfield, N.J., Brown, Penelope, Englert, Christina, Hayashi, Makoto, Heinemann, Trine, Hoymann, Gertie, Rossano, Federico, de Ruiter, J.P., Yoon, Kyung-Eun, Levinson, Stephen C., 2009. Universality and cultural specificity in turn-taking in conversation. Proceedings of the National Academy of Science 106, 10587-10592.

Stivers, Tanya, Hayashi, Makoto, 2010. Transformative answers: one way to resist a question's constraints. Language in Society $39,1-38$.

Stivers, Tanya, Robinson, J.D., 2006. A preference for progressivity in interaction. Language in Society 35, 367-392.

Stivers, Tanya, Rossano, Federico, 2010. Mobilizing response. Research on Language and Social Interaction 43, 1-31.

Weber, Elizabeth, 1993. Varieties of Questions in English Conversation. John Benjamins, Amsterdam.

Tanya Stivers was a staff scientist in the Language and Cognition Group, Max Planck Institute for Psycholinguistics, Nijmegen. She studies the organization of social interaction using conversation analysis and multi-method approaches. She is author of Prescribing Under Pressure: Parent-Physician Interaction and Antibiotics (2007; Oxford University Press) and is co-editor (with N.J. Enfield) of Person Reference in Interaction: Linguistic, Cultural and Social Perspectives (2007;

Cambridge University Press) and co-editor (with L. Mondada and J. Steensig) of The Morality of Knowledge in Conversation (2010; Cambridge University Press). 